\title{
Assessing the Potential for a National Print Repository: Results of an Australian Overlap Study
}

\section{Paul Genoni and Eva Varga}

This paper reports on research assessing the potential space savings that can be made if Australian academic libraries implement a national repository for the storage of legacy print collections. The paper includes data derived from a collection overlap study based on members of the CARM (CAVAL Archival and Research Materials) Centre to estimate the impact of a fully implemented national repository. It includes a calculation of the shelf and floor space that libraries might potentially retrieve for other purposes.

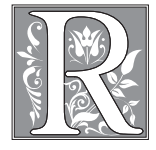

esearch libraries have long depended on remote, highdensity storage to deal with expanding collections and lack of storage space in their primary library site. ${ }^{1}$ Increasingly, remote storage is seen not only as a necessity required to manage local space shortages but also as a desirable means of reducing the high cost associated with indefinitely storing lowuse print material. For many libraries, it is apparent that the long-established but expensive practice of storing little-used materials "just-in-case" they are required is unsustainable. The savings made by using remote storage more than compensates for the inconvenience incurred by some users as they wait to access stored items.

The pressure to minimise long-term storage costs has led libraries to embrace ways in which the expenses associated with remote storage can be further reduced. This has been achieved in two ways. First, by the implementation of increasingly high-density forms of storage; and second, by libraries collaborating to share the costs associated with acquiring, managing, and maintaining a storage facility. The result is a steady rise in the number of collaborative or federated facilities, sometimes referred to as print repositories. ${ }^{2}$ The use of print repositories not only reduces the space and cost pressures associated with longterm print storage; it can also benefit users by optimising the efficiency of discovery and delivery of low-use print material. This has led to the implementation of national print repositories in several European countries ${ }^{3}$ and to other countries implementing increasingly broad-based regional repositories.

Despite the apparent benefits to be gained from federated print storage, there are issues that to date have prevented this solution from being implemented in Australia. Some of these issues are

Paul Genoni is Senior Lecturer in the School of Media, Culture and Creative Arts at Curtin University of Technology; e-mail: p.genoni@curtain.edu.au. Eva Varga is CARM Centre Manager at CAVAL Ltd; Eva.varga@caval.edu.au. 
related to the relationships between the nation's research libraries and their access to government funding for research infrastructure, ${ }^{4}$ and perhaps others have more to do with pride in collection size and lingering competitiveness between institutions. There is also another set of issues, based around the uncertainty of the extent of the benefits that might be delivered by a broad-based print repository. The purpose of this paper is to explore this latter issue - in particular, to attempt to calculate, in broad terms at least, the potential space savings that might be made if libraries were to implement a national print repository as a means of federating remote storage and maximising deduplication between collections.

\section{Recent International Studies of Federated Storage}

The rising interest in long-term print storage has been evidenced by a recent series of international reports on the issue. These reports have been unequivocal in their support of the concept of collaborative print storage.

In the United States, Bernard Reilly undertook a 2003 study on behalf of the Council on Library and Information Resources. Reilly's account of the storage practices of U.S. research libraries was placed in the context of international moves toward large-scale repositories, some of which were being implemented on a national basis. He reported the increased use of repositories in the United States, noting the details of a number of examples that had developed on either a geographic (state) or shared interest (consortium) basis. Reilly noted that "the repositories were the response of governing authorities to a system-wide space crisis, ${ }^{15}$ and concluded that:

With the appropriate resources in place, one could imagine the major North American research libraries, regional repositories, and national-level repositories linked in a network that enables strate- gic management of the important primary resources for scholarship. ${ }^{6}$

In 2007 Lizanne Payne prepared a report commissioned by OCLC, Library Print Facilities and the Future of Print Collections in North America. Payne investigated the current print storage activities of North American academic libraries, reporting that there were some 68 highdensity storage facilities (both independent and shared), housing in excess of 70 million volumes. She believes that:

...high-density library storage facilities have moved into the mainstream for collection management in academic libraries, and that this is the optimum time for the academic and library communities to leverage this collective capacity to develop a broader, system-wide approach to maintaining print collections across institutional boundaries. ${ }^{7}$

Payne's argument is built on the efficiencies in storage, discovery, and delivery that are obtained from collaborative repositories, and she raises the question as to the appropriate scale of the "systemwide approach."

Academic institutions and the libraries that serve them could provide lasting benefits to scholarship and economies to their institutions by proactively developing a network of print repositories on a regional, national, or even global scale. ${ }^{8}$

The Association of Research Libraries (ARL) has also sponsored recent U.S. research with a view to reporting on the evolving space utilisation by member institutions. The data collected in the survey updates previous similar surveys conducted under the auspices of the ARL. ${ }^{9}$ The most recent of these reports notes that, consistent with conclusions reached by other observers, ${ }^{10}$ U.S. research libraries are relying increasingly on remote and 
federated storage as a means of addressing space shortages.

\begin{abstract}
ARL member libraries' use of remote shelving facilities as a response to space needs has increased since 1998 and, judging from the responses to this survey, this trend will continue. Another upward trend is the use of shared facilities... ${ }^{11}$
\end{abstract}

A further North American survey of print repositories has recently been commissioned by the Canadian Association of Research Libraries Committee on Scholarly Communication. The survey described "the more prominent Canadian university library print repository initiatives."12 These included eight single university repositories and four shared repositories. The report indicates a trend toward larger scale repositories. The two shared repositories established in the 1990s had two and three members, while those being established at the time of the report consist of 20 (Ontario Council of University Libraries: Collaborative Collection Continuity Initiative) and 17 (Council of Atlantic University Libraries: Atlantic Regional Consortium for the Preservation of Scholarly Materials) members.

In the United Kingdom, the Higher Education/British Library Task Force commissioned a 2001 report on future storage options. The report noted the "powerful theoretical arguments for the development of collaborative storage facilities over the last decade along with a strong and developing practice toward the end of the last decade." ${ }^{13}$ CHEMS Consulting subsequently undertook a 2005 survey on behalf of the Consortium of Research Libraries in the British Isles (CURL) and the British Library. The responding libraries consisted of 38 higher education libraries and four large municipal libraries. Extrapolating from responses received from the higher education libraries, the CHEMS report calculated that the total sector would suffer a storage shortfall of up to 455 linear kilometres (282.5 linear miles) by 2015, and that the capital cost of providing space to meet this shortfall would be 103 million pounds. ${ }^{14}$

In response to this impending crisis, CHEMS Consulting recommended a model for a national collaborative storage strategy, which is now being adopted in stages. The creation of the "U.K. Research Reserve" is based on the existing lending collections of the British Library supported by a group of six academic research libraries. Phase 1 of the project (running from January 2007 to June 2008) has focused on journals. The projected Phase 2 will invite the participation of other research libraries and possibly expand the scheme to include monographs. ${ }^{15}$ The intention is to ensure the preservation of a designated number of copies in the Reserve and thereby encourage substantial freeing up of space as libraries deduplicate, confident that items will be retained in perpetuity and can be borrowed as required.

The issue of federated storage is also being canvassed in Asia, with recent research from South Korea recommending that "a model for a national collaborative repository should be adopted" in that country. Hee-Yoon Yoon and Sun-Kyung Oh suggest that this repository should encompass all library types, and that the major unresolved question is "whether this role should be given to regional representative libraries or if a separate national collaborative repository is required." 16

The issue of print storage, including the prospect of creating collaborative repositories, has been debated in Australia over the past decade. ${ }^{17}$ The Council of Australian University Librarians (CAUL) in particular has considered the matter, and their deliberations included convening a National Cooperative Store Workshop in $1999 .{ }^{18}$ The matter was actively before CAUL until 2004, when the momentum dissipated amidst internal disagreements and pessimism regarding the prospect of government funding. The matter of Australian print storage has, 
however, continued to receive attention from outside CAUL. ${ }^{19}$

\section{Australian Collection Overlap Studies}

If Australian research libraries are to support the creation of a national print repository, it would be with a view to achieving savings in the cost of long-term storage of print material and in producing benefits to researchers by creating efficiencies in the digital discovery and delivery of print items.

Calculations regarding the extent of the space savings that might be made with regard to long-term storage depend on two factors: first, the space saved by implementing state-of-the-art highdensity storage systems; and second, the potential to deduplicate collections and permanently dispose of material. In both regards, the calculations are difficult and necessarily require a degree of informed guesswork. Estimates must often be made by relying on incomplete data and on various suppositions regarding local demand (for instance: Can a library afford to surrender a locally held copy?). The problem of making accurate assessments has been experienced elsewhere. The Higher Education/British Library Task Force report had acknowledged that, although it appears to be "intuitively true" that national or regional repositories will reduce storage costs, it is nonetheless "difficult to uncover any cost/benefit analyses of cooperative or collaborative storage." ${ }^{20}$ The CHEMS report made a similar point, noting that the creation of a national repository was being recommended despite there being "no available evidence of the amount of deduplication and space saving that could be achieved." 21

The data that can provide relevant evidence regarding the potential for deduplication and deposit (and thereby possible space saving) are those that measure collection overlap. There have been two major overlap studies undertaken in Australia in recent years that provide useful background data regarding duplication of monographs.
In 2002, the National Library of Australia (NLA) was commissioned by the Department of Education, Science and Training (DEST) to conduct a survey of collection overlap between Australian university libraries. The compilation of the overlap data was said to be important as part of the information gathering that could "assist decision-making in a range of areas including co-operative storage ventures." 22 The survey included both monographs and serials, with the NBD records and holdings statements again serving as the data source. The account of the research warned, however, that "Data quality is an issue which needs to be noted," ${ }^{23}$ largely due to the duplication of records and the incompleteness of the holdings data.

The report itself concentrates more on describing the levels of unique holdings than on the degree of overlap, and the evaluation of the data is presented on a state-by-state rather than a national basis. Therefore, despite the conclusion that "there is a high degree of uniqueness among collections of academic institutions," ${ }^{24}$ there is no attempt to establish a yardstick as to what constitutes "high" or "low" with regard to the number of unique holdings. As is often the case with overlap studies, the results are open to differing interpretations; and, in this case, another reading of the data reveals the extent of the overlap. For example, although the report reveals there were $6,675,693$ monograph titles that were unique within a state, there were also $5,272,884$ holdings that were duplicates within a state..$^{25}$ This number of duplicates would inevitably be significantly greater if calculated nationally; and it is apparent that as demand declines for many titles, as they age, the scope for deduplication will be considerable.

A second major DEST-supported study with an overlap component was also undertaken in 2002 and 2003. This was the Australian Research Libraries Collection Analysis Project (ARLCAP), which analysed the collections of the "Group 
of Eight" libraries (serving Australia's most established and research-intensive universities), and the NLA, focusing on collections from the humanities and social sciences. In a survey of 412,120 monograph records that were within the subject scope of the ARLCAP study and had holdings for at least one of the participating libraries, it was found that 158,412 ( $38.4 \%)$ were uniquely held $(80,565$ by the NLA and 77,847 by the combined university libraries). For these records there were, however, some 791,827 duplicates held by the nine libraries, with an average of 3.003 holdings per record. ${ }^{26}$

Consideration was given in the ARLCAP report to various future cooperative scenarios for building national research infrastructure, including storage of legacy print collections. The two key scenarios were based on the "Nationalist approach," which "has as its main objective to make Australia as independent as it can be in its research information provision", 27 and the "Internationalist approach," which is "dominated by the notion that overseas... collections are, and always will be, much greater than Australian collections, and that the number of items that are unique in Australia is so low that the most cost-effective strategy is to rely entirely on providing access to these collections rather than replicate them in Australia." ${ }^{28}$ The report found that an implication of choosing the nationalist approach would be that:

\begin{abstract}
Storage facilities should be established to ensure that now and in the future no titles held in Australia should be discarded. These facilities might involve existing infrastructure or might involve the creation of new ones. ${ }^{29}$
\end{abstract}

The ARLCAP report also concluded that:

There is no evidence from the study that widespread relocations of stock between libraries or to a shared stor- age facility, other than the transfer of stock to the National Library, would be a cost-effective enhancement of the research infrastructure. ${ }^{30}$

On the basis of the data presented in the report, it is not possible to see the evidence or justification for this conclusion, as the study made no attempt to establish what might be meant by "cost-effective" in this context. There is no assessment of the cost associated with long-term duplicated storage of low-use material, or of the effectiveness of discovery and delivery of such material in a widely distributed system.

A further conclusion from the ARLCAP study was more sustainable; that is, that "Any national storage facility cannot sensibly be restricted to the higher education sector." 31 This is an acknowledgment of the critical role played by the collections of the NLA (the survey found their collections were 56.4 percent unique for monographs), but also of the potentially important roles to be played by other nonuniversity research libraries.

\section{Study of CARM Member Overlap}

The aim of the present research is to undertake estimates of the amount of space that might potentially be "saved" if Australian research libraries committed to a fully implemented national print repository. "Fully implemented" in this context refers to a repository in which:

- ownership of deposited material is transferred to the repository;

- the repository commits to the permanent retention of deposited material;

- access to stored material is guaranteed and supported by state-of-the-art discovery and delivery systems.

These features are necessary to achieve optimum storage densities and to encourage participating libraries to deduplicate their local collections.

Neither of the two major Australian shared storage facilities has yet met these conditions in full. The first of these repositories-established in 1984-is the 
Universities' Research Repository South Australia (URRSA), which serves a consortium consisting of the University of Adelaide, Flinders University, and the University of South Australia. URRSA simply stores material on behalf of participating libraries. ${ }^{32}$ There is no transfer of ownership or attempt to deduplicate the store, and no onus on participating libraries to retain material indefinitely or to support access with high-end technologies.

The second - and most high-profileAustralian repository is the CARM (CAVAL Archival and Research Materials) Centre, managed by CAVAL Ltd. CAVAL is a not-for-profit consortium, owned by 11 Australian universities, providing services to the Australian library sector (chiefly, but not wholly, within the state of Victoria). The CARM Centre is located in outer-Melbourne on land owned by La Trobe University and has been providing storage services to member libraries since 1997. CARM has a capacity of approximately one million volumes, with an expansion to commence soon that will treble the current space. CARM is closer than URSSA to the fully implemented repository model in that libraries may choose to cede ownership to the "CARM Collection" in its role as a last-copy repository. As of April 2008, the CARM Collection included 246,391 nonserial titles and approximately 300,000 volumes of serials. The facility is, however, also used for print storage by libraries leasing space for the purpose and retaining ownership of the stored material. It is relevant that the business model for the forthcoming expansion to the CARM facility is based on libraries leasing space for storage rather than ceding ownership to the CARM Collection. The decision by libraries to retain ownership is likely to be based on:

- the belief that items may at some future time be reincorporated with the main collection if priorities change or more space becomes available;

- institutional accounting practices that prevent the transfer of ownership;
- a competitive desire to retain a high count of "owned" titles and volumes.

With the CARM Centre providing the only facility for transferred ownership, it was therefore decided to attempt to estimate the space that member libraries could save if they were to cede ownership of low-use books to CARM as a precursor to deduplication. Books were chosen as the focus of the study for several reasons. First, the task of estimating the space implications of book duplication is more achievable than with journals where the amount of space consumed by titles cannot be estimated on the basis of holdings records only. Second, the rapidly expanding availability of journal backsets in secure digital form means that the "International approach" is less contentious for this material. The decline of the scholarly journal in print form is irreversible, and the technologies of article discovery and delivery have to a large extent already been "internationalised." The situation with books and other monographs is far less clear. After a period of decline in the 1990s, the rate of acquisition of print books by Australia's academic libraries has recovered to near record highs, and this trend appears likely to continue. ${ }^{33}$

It was therefore decided to undertake a study of monographs that met the following criteria:

- Dewey class number in the 600s;

- published prior to 1990;

- owned by one or more of the CARM member libraries.

The Dewey 600s - which include technology, medicine, engineering, agriculture, management, and building and construction - were chosen as it was known that the largest of the CARM member libraries (La Trobe, Melbourne, and Monash) have substantial holding in these subjects. As the purpose of the study was to assess the potential for deduplication, it was also believed that these subject areas included material that would date more rapidly than some others and would therefore be available to be relegated to storage or withdrawn 
from collections. It is also the case that the nature of the subjects included in the 600 s would invariably mean that many items would be published overseas and therefore not include a high percentage of material for which the NLA and state libraries had responsibility for ensuring permanent retention (as would be the case, for example, with the 800 s or 900 s). It is not suggested that results from a study based on the 600s would necessarily be duplicated in other classes.

The overlap study was undertaken for two categories of material: first, for records that included a holding for the CARM Collection (that is, a copy of the item has already been ceded to the CARM Collection for permanent retention); second, for records held by at least one member library but for which there is no current holding in the CARM collection.

The data was provided by the National Library of Australia and based on a search of the Libraries Australia database undertaken in April 2007. Libraries Australia is the most comprehensive data source available; but, as previous studies have found, it is prone to some degree of error. The principal causes of error are: duplication of records for the same item; incomplete holdings; and failure by libraries to amend records to reflect the current status of an item.

\section{Overlap for Items Included in the CARM Collection}

The CARM Collection consists of items for which ownership has been transferred from a member library to CARM. The collection has been deduplicated, so that only one copy of any item is retained. The overlap for items among member libraries was first calculated for items held in the CARM Collection, with a Dewey 600 class number and pre-1990 publication. There are currently 22,408 titles in the CARM Collection matching these criteria.

The 22,408 records have an average of 2.6 holdings per record, and the total number of duplicate holdings held by CARM member libraries is 35,749 .

\begin{tabular}{|c|c|c|}
\hline \multicolumn{3}{|c|}{ TABLE 1 } \\
Duplication of CARM \\
Collection Monographs \\
\hline \hline No. Records & No. Holdings & \% \\
\hline 7,954 & CARM only & 35.50 \\
\hline 5,209 & CARM +1 & 23.25 \\
\hline 3,527 & +2 & 15.74 \\
\hline 2,436 & +3 & 10.87 \\
\hline 1,550 & +4 & 6.92 \\
\hline 898 & +5 & 4.01 \\
\hline 504 & +6 & 2.25 \\
\hline 217 & +7 & 0.97 \\
\hline 79 & +8 & 0.35 \\
\hline 30 & +9 & 0.13 \\
\hline 3 & +10 & 0.01 \\
\hline 1 & +11 & 0.00 \\
\hline $\mathbf{2 2 , 4 0 8}$ & $\mathbf{5 8 , 1 5 7}$ & \\
\hline
\end{tabular}

\section{Overlap for Items Not Included in the CARM Collection}

The overlap for items (Dewey 600s, pre1990 publication) was also calculated for items not held in the CARM Collection, but owned by one or more member libraries.

\begin{tabular}{|c|c|c|}
\hline \multicolumn{3}{|c|}{$\begin{array}{c}\text { TABLE } 2 \\
\text { Duplication of Non-CARM } \\
\text { Collection Monographs }\end{array}$} \\
\hline No. Records & No. Holdings & $\%$ \\
\hline 139,638 & 1 & 62.26 \\
\hline 38,911 & 2 & 17.35 \\
\hline 19,681 & 3 & 8.77 \\
\hline 11,453 & 4 & 5.11 \\
\hline 6,679 & 5 & 2.98 \\
\hline 3,938 & 6 & 1.76 \\
\hline 2,134 & 7 & 0.95 \\
\hline 1,053 & 8 & 0.47 \\
\hline 510 & 9 & 0.23 \\
\hline 231 & 10 & 0.10 \\
\hline 59 & 11 & 0.03 \\
\hline 1 & 12 & 0.00 \\
\hline 224,288 & 410,261 & \\
\hline
\end{tabular}


The 224,288 records have an average of 1.83 holdings per record, and the total number of duplicate holdings is $185,973$.

In total, there are 246,696 records with the Dewey class 600 published before 1990 and owned by CARM or a CARM member library. This "system" of libraries is recorded as having 221,722 duplicates for these titles.

These figures do not, of course, allow a precise calculation of the amount of space that could be saved in practice. They do, however, help establish the extent of the potential saving under different scenarios. For example, in the extreme case, member libraries could, as a matter of policy, choose to deposit one copy of each title in the study sample (Dewey 600s, pre-1990 publication) with the CARM Collection and divest all duplicate copies. This would add 224,288 titles to the CARM Collection, while leading to a reduction of $446,010(35,749+410,261)$ titles shelved by the member libraries. Table 3 calculates the approximate amount of shelving that could be retrieved by such a strategy.

Calculating space required for library storage is a task bedeviled by numerous variables, ${ }^{34}$ and there are a number of recommended formulae. The following calculations are based on 1.2 volumes per title (record), shelved at 30 volumes per linear metre (approx. 27 volumes per linear yard). ${ }^{35}$

\begin{tabular}{|c|c|c|}
\hline \multicolumn{3}{|c|}{$\begin{array}{c}\text { TABLE } 3 \\
\text { Potential Reduction in Shelving: } \\
\text { CARM Members }\end{array}$} \\
\hline $\begin{array}{l}\text { No. } \\
\text { Items }\end{array}$ & $\begin{array}{c}\text { No. } \\
\text { Volumes }\end{array}$ & $\begin{array}{c}\text { Shelving } \\
\text { (Linear Metres/ } \\
\text { Yards) }\end{array}$ \\
\hline 446,010 & 535,212 & $17,840 / 19,053$ \\
\hline
\end{tabular}

The projected "saving" is therefore nearly 18 kilometres (11.2 miles) of shelving.

The other important figure to be calculated from this data relates to the floorspace needed to accommodate this shelving. A recent estimate is that conventional library storage can house
145 volumes per square metre (121 per square yard), as compared to high-density repository storage of 373 volumes per square metre (312 per square yard). ${ }^{36}$ Based on these figures, the saving in library floorspace would amount to some 3,691 square metres (4,429 square yards), which could be replaced by 1,434 square metres $(1,721$ square yards) of repository floorspace. This already substantial saving is magnified by the significantly higher cost-estimated at "a factor of five or six times" - of building and maintaining conventional library space as opposed to repository space. ${ }^{37}$

If this result were repeated across all ten Dewey class divisions, the total savings would be on the order of 178 kilometres (110.5 miles) of shelving, requiring 36,910 square metres ( 44,292 square yards) of floorspace. There are reasons why it is unsafe to extrapolate this result to other class divisions-difference in the volume of publication, high likelihood of differing patterns of duplication - but it is clear that the potential for space saving is significant.

It is also not suggested that these projected savings in terms of shelving and floorspace are immediately achievable. A defining characteristic of research libraries is the depth and richness of their content, and individual libraries will rightly strive to retain research quality print collections. It is the case, however, that an increasing number of Australian academic libraries have reached a "steady state" in terms of collection size and are looking to store or dispose of older monographs to manage their local space problem. ${ }^{38}$ This response is likely to be ongoing and will achieve the best outcomes-in terms of space savings for libraries and continued access for researchers - if it is managed and collaborative.

\section{“Three Library” Study}

Three libraries were selected for a closer study of overlap between a subset of the CAVAL member libraries, to further investigate the impact of a systemwide repository on local users. La Trobe, 
Melbourne, and Monash were chosen on the basis that they represented the three largest of the Melbourne-based libraries, and all three were known to have goodto-strong holdings in the 600s. Again, this data covers the Dewey 600s, with publication prior to 1990 .

\begin{tabular}{|l|c|c|}
\hline \multicolumn{3}{|c|}{ TABLE 4 } \\
Unique Holdings \\
\hline \hline La Trobe & 10,092 & $9.7 \%$ \\
\hline Melbourne & 24,170 & $23.3 \%$ \\
\hline Monash & 7,907 & $7.6 \%$ \\
\hline & $\mathbf{4 2 , 1 6 9}$ & $\mathbf{4 0 . 6 \%}$ \\
\hline
\end{tabular}

\begin{tabular}{|l|c|c|}
\hline \multicolumn{3}{|c|}{ TABLE 5 } \\
Held by Two Libraries \\
\hline \hline $\begin{array}{l}\text { La Trobe \& } \\
\text { Melbourne }\end{array}$ & 18,605 & $18.0 \%$ \\
\hline $\begin{array}{l}\text { La Trobe \& } \\
\text { Monash }\end{array}$ & 15,864 & $15.3 \%$ \\
\hline $\begin{array}{l}\text { Melbourne } \\
\text { \& Monash }\end{array}$ & 18,328 & $17.7 \%$ \\
\hline & $\mathbf{5 2 , 7 9 7}$ & $\mathbf{5 1 . 0 \%}$ \\
\hline
\end{tabular}

\begin{tabular}{|l|c|c|}
\hline \multicolumn{3}{|c|}{ TABLE 6 } \\
Held by Three Libraries \\
\hline \hline $\begin{array}{l}\text { La Trobe, } \\
\text { Melbourne, } \\
\text { \& Monash }\end{array}$ & 8,669 & $8.4 \%$ \\
\hline
\end{tabular}

There is a total of 103,635 records for the three libraries, with 70,135 duplicate holdings, for an average of 1.68 holdings per record.

These figures indicate the extent of duplication of low-use material (see lending data reported below) between libraries located within the same metropolitan area and teaching in the same broad areas. ${ }^{39}$ Nearly 60 percent of titles are held in two or more copies, and over 40 percent of shelf space is consumed by duplicate holdings. It is again possible to calculate the effect of the extreme case

\begin{tabular}{|c|c|c|}
\hline \multicolumn{3}{|c|}{ TABLE 7 } \\
Potential Reduction in Shelving \\
\hline \hline No. Titles & $\begin{array}{c}\text { No. } \\
\text { Volumes }\end{array}$ & $\begin{array}{c}\text { Shelving } \\
\text { (Linear Metres/ } \\
\text { Yards) }\end{array}$ \\
\hline 173,770 & 208,524 & $6,951 / 7,577$ \\
\hline
\end{tabular}

(depositing single copies with the CARM Collection and removing duplicates) by which the libraries would divest 173,770 titles.

In this case, the number of volumes would require approximately 1,438 square metres (1,726 square yards) of library floorspace, or 559 square metres (671 square yards) in a repository.

\section{Local Demand (Lending) for Dewey 600s, pre-1990}

To understand the impact on local users of such a response, it is necessary to attempt to assess the local demand for this material. To measure the local demand for items that might potentially be deposited or discarded, lending figures for the full year 2007 were obtained from La Trobe, Melbourne, and Monash. These figures were again for the Dewey 600s, both for pre-1990 publications and for publications from 1990 and after. ${ }^{40}$

As would be expected, these figures indicate a significant decline in demand for older material. Across the three universities, 88.95 percent of the borrowing is accounted for by the material published in 1990 or later, and only 11.05 percent by the material published earlier. For the two libraries for which a figure is available, only just over 10 percent of individual

\begin{tabular}{|l|c|c|c|}
\hline \multicolumn{5}{|c|}{ TABLE 8 } \\
\multicolumn{2}{|c|}{ Lending, Dewey 600s, Pre-1990 Monographs } \\
\hline \hline & Items & $\begin{array}{c}\text { No. Items } \\
\text { Loaned (\% } \\
\text { of Items) }\end{array}$ & $\begin{array}{c}\text { No. Loans (\% } \\
\text { of All Loans) }\end{array}$ \\
\hline La Trobe & 106,987 & $11,597(11)$ & $16,961(14.2)$ \\
\hline Melbourne & 86,937 & & $21,897(11.6)$ \\
\hline Monash & 117,826 & $13,980(12)$ & $19,979(8.9)$ \\
\hline & $\mathbf{3 1 1 , 7 5 0}$ & & $\mathbf{5 8 , 8 3 7}(\mathbf{1 1 . 0 5})$ \\
\hline
\end{tabular}


items published prior to 1990 were borrowed within the 12 months.

TABLE 9

Lending, Dewey 600s, 1990+ Monographs

\begin{tabular}{|l|c|c|c|}
\hline \hline & Items & $\begin{array}{c}\text { No. Items } \\
\text { Loaned (\% } \\
\text { of Items) }\end{array}$ & $\begin{array}{c}\text { No. Loans (\% } \\
\text { of All Loans) }\end{array}$ \\
\hline La Trobe & 85,647 & $29,951(35)$ & $102,443(85.8)$ \\
\hline Melbourne & 71,869 & & $167,295(88.4)$ \\
\hline Monash & 116,018 & $65,822(57)$ & $204,049(91.1)$ \\
\hline & $\mathbf{2 7 3 , 5 3 4}$ & & $\mathbf{4 7 3 , 7 8 7}(\mathbf{8 8 . 9 5})$ \\
\hline
\end{tabular}

mean the outcomes would vary if other parameters were substituted. Nevertheless, the results of the study are defensible in terms of the goal of producing evidence that could inform decisions regarding the establishment of a national print repository.

What the data in this paper indicate is that there is considerable scope for a reduction in local, duplicated, high-cost storage. It is apparent that the scope for space savings for individual libraries is impor-

These results indicate it is likely that, for each of the universities, a significant amount of the pre-1990 material will not be borrowed, even over an extended period. It is also likely that even this current modest level of borrowing of pre-1990 publications will decline further as the material continues to date.

There is, nonetheless, residual demand for older material, although it is unclear if this demand is item-specific or if borrowers are simply selecting "something" that appears to be on topic and are perhaps unaware of the year of publication of their chosen text. And, if demand is item-specific, it is unclear if this needs to be met immediately or if users would be prepared to wait a short period for delivery from a repository source. These matters would require further investigation before a more sophisticated assessment could be made of the likely impact of transferring older material to a repository collection such as CARM.

\section{Discussion and Conclusion}

The research reported in this paper is indicative only and needs to be read in the context of other available evidence. As discussed, the primary data source, Libraries Australia, although the best available, is by no means completely accurate. There have also been some decisions made in gathering the data-for example, the choice of the Dewey 600s, and the selection of 1990 as a "cut off" date - that tant and that, when extrapolated across the system, these savings are potentially substantial. In the short term, this can produce a benefit by releasing space currently used for print storage for other uses; but, over the longer term, it translates into a real financial saving for institutions as they defer the need for new or expanded buildings and reduce their outlay on print storage.

The extent to which Australian academic libraries are already (and increasingly) relying upon withdrawal of nonserial material to manage space problems has recently been reported. ${ }^{41}$ While this withdrawal is necessary for local collection management, it is proceeding with little consideration for developing the form of print storage that is necessary to either reduce the cost burden on research institutions or to optimise the discovery and delivery of this material for the benefit of the nation's research community. Currently the management of Australia's legacy print collections is proceeding in something of a policy vacuum, with responses that are local and expedient rather than systemwide and sustainable.

This is at a time when managers of Australia's research infrastructure are promoting the use of collaborative, crossinstitutional management of the nation's research assets. As the National Collaborative Research Infrastructure Strategy Committee recently concluded, "Major infrastructure should be developed on 
a collaborative, national, non-exclusive basis." ${ }^{42}$ The drivers in the implementation of research infrastructure are both cost and benefit, with national collaboration seen as favourable to both sides of the equation.

While the research reported in this paper has focused largely on the costs associated with storage, there is also considerable scope for research and discussion on the service benefits that can derive from the implementation of a national print repository. Australian research libraries provide services in a very particular environment, characterised in international terms by a small research population; a fully developed and regulated higher education system; a centralised and government-led system of funding for research and research infrastructure; libraries of moderate collection strength; affordable high-end technologies; and a large geographic area. These various circumstances will impact upon the type and scale of storage and repository infrastructure that might conceivably be implemented. The challenge for the Australian research library sector is to ensure that national initiatives are not confined to e-research infrastructure only and that they continue to promote the national importance and research value of legacy print collections. This will require the sector to engage with the research community to fully understand their evolving service needs and to ensure that any developments that are undertaken will meet the needs of researchers.

Despite the ongoing development of the CARM Collection, Australia is beginning to look out-of-step with countries that are more actively implementing broad-based print repository collections and services. The explanation for this might be found in the ARLCAP Report and its dual scenarios of the "nationalist approach" and the "internationalist approach." It may be that Australia's academic libraries, having failed to build an independent research capacity or to reach agreement on a national approach to print storage, have de facto accepted that their future lies in adopting the internationalist approach. Since the ARLCAP Report was concluded, the advent of mass digitisation programs for print monographs (notably-but not only-Google Print) may have given further impetus to the internationalist approach, perhaps convincing those in doubt that digital technologies will render the e-book as ubiquitous and as accessible as the e-journal.

If it is the case that Australia's research libraries have decided to adopt the internationalist approach, then this should be made clear to the relevant government departments and the research community. If, however, it is believed to be in the national interest that Australia's research infrastructure should be as autonomous as possible, then legacy book collections should be stored as cost-effectively, securely, and accessibly as possible. This will be achieved when the following conditions are present: minimisation of local and systemwide costs associated with long-term storage; certainty about the retention of individual titles; and stateof-the-art support for digital discovery and delivery of legacy print collections. These outcomes will be best achieved in a collaborative storage environment built around a fully implemented national print repository.

\section{Notes}

1. David Block, "Remote Storage in Research Libraries," Library Resources and Technical Services 44 , no. 4 (2000): $184-89$.

2. A "store" can be differentiated from a "repository." In a shared store, libraries retain ownership of items; in a repository, ownership is ceded to the consortium or other body that owns and/or manages the facility.

3. Johan Henden, "The Norwegian Repository Library," Library Management 26, no. 1/2 (2005): 7378; Pentii Vattulainen, "National Repository Initiatives in Europe," Library Collections, Acquisi- 
tions, \& Technical Services 28, no. 2 (2004): 39-50.

4. Paul Genoni, "Towards a National Print Repository for Australia: Where from and Where to?" Australian Academic \& Research Libraries 38, no. 2 (2007): 84-98.

5. Bernard F. Reilly, Developing Print Repositories: Models for Shared Preservation and Access (Washington, D.C.: Council on Library and Information Resources, 2003): 6. Available online at www.clir.org/pubs/reports/pub117/pub117.pdf. [Accessed 23 February 2009].

6. Ibid., 40 .

7. Lizanne Payne, Library Storage Facilities and the Future of Print Collections in North America (Dublin, Ohio: OCLC, 2007): 5. Available online at

www.oclc.org/programs/publications/reports/2007-01.pdf. [Accessed 23 February 2009].

8. Ibid., 26.

9. Cornell University Libraries, A Survey of Compact Storage Facilities and Collections in the Member Libraries of the Association of Research Libraries (ARL): A Preliminary Report SPEC Kit 39 (Washington, D.C.: Systems and Procedures Exchange Center, 1978); Virginia Steel, Remote Storage: Facilities, Materials Selection and User Services, SPEC Kit 164 (Washington, D.C.: Association of Research Libraries, 1990); Jan Merrill-Oldham and Jutta Reed-Scott, Library Storage Facilities, Management, and Services, SPEC Kit 242 (Washington, D.C.: Association of Research Libraries, 1999).

10. Maureen Pastine, Jean Dorrian, and Ann Dougherty, "The Need for New Space and Storage Facilities," Library Issues 20, no. 1 (1999): 1-4; Ron Chepesiuk and David Weeks, "The Harvard Model and the Rise of Shared Storage Facilities," Resource Sharing and Information Networks 16, no. 2 (2002), 159-68; Lizanne Payne, "Depositories and Repositories: Changing Models of Library Storage in the USA," Library Management 26, no.1/2 (2005): 10-17; Jim Agee and Sarah Naper, "Off-site Storage: An Analysis," Collection Building 26, no. 1 (2007): 20-25.

11. Thomas C. Deardorff and Gordon J. Aamot, Remote Shelving Services, SPEC Kit 295 (Washington, D.C.: Association of Research Libraries, 2006): 15.

12. Canadian Association of Research Libraries, Print Repository Initiatives at Canadian University Libraries: An Overview 2006. Available online at www.carl-abrc.ca/projects/preservation/pdf/ print_repos_overview.pdf. [Accessed 23 February 2009].

13. Steve O'Connor, Andrew Wells, and Mel Collier, "A Study of Collaborative Storage of Library Resources," Library Hi-Tech 20, no. 3 (2002): 258-69.

14. CHEMS Consulting, Optimising Storage and Access in UK Research Libraries: A Study for CURL and the British Library 2005: 47. Available online at

www.curl.ac.uk/about/documents/CURL_BLStorageReportFinal-endSept2005.pdf. [Accessed 23 February 2009].

15. Nicola Wright, "Protecting the UK's Research Collection: The UK Research Reserve Project," SCONUL Focus 40 (2007): 38-40.

16. Hee-Yoon Yoon and Sun-Kyung Oh, "Shortage of Storage Space in Korean Libraries: Solutions Centering upon Hub-based Collaborative Repositories," Aslib Proceedings 60, no. 3 (2008): 277.

17. Genoni, "Towards a National Print Repository for Australia."

18. Council of Australian University Librarians, A National Cooperative Store Network: Workshop Convened by CAUL: Flinders University, Adelaide, 6 August 1999. Available online at www.caul.edu. au/meetings/Store990806.min.doc. [Accessed 23 February 2009].

19. Steve O'Connor, "Collaborative Strategies for Low-use Research Materials," Library Collections, Acquisitions \& Technical Services 28, no. 1 (2004): 51-57; Paul Genoni, "Towards a National Print Repository for Australia"; Paul Genoni, "Current and Future Print Storage for Australian Academic Libraries: Results of a Survey," Library Collections, Acquisitions \& Technical Services 32, no. 1 (2008): 31-41; Cathie Jilovsky and Paul Genoni, "Changing Library Spaces: Finding a Place for Print," Libraries/Changing Spaces: Virtual Places: 12th Biennial Conference and Exhibition of the Victorian Association for Library Automation, Melbourne, February 5-7, 2008. Available online at www. vala.org.au/conf2008.htm. [Accessed 23 February 2009]. 265.

20. O'Connor, Wells, and Collier, "A Study of Collaborative Storage of Library Resources,"

21. CHEMS Consulting, Optimising Storage and Access in UK Research Libraries, 14.

22. Roxanne Missingham and Robert Walls, "Australian University Libraries: Collections Overlap Study," Australian Library Journal 52, no. 3 (2003): 248.

23. Ibid., 252.

24. Ibid., 255.

25. This figure is extrapolated from Missingham and Walls, "Australian University Libraries: Collections Overlap Study," 252 (Table 2).

26. These figures are extrapolated from Australian Research Libraries Collection Analysis Project, Report 2004: 41. Available online at 
www.library.uwa.edu.au/_data/assets/pdf_file/0015/3741/arlcap_final_report.pdf. [Accessed 23 February 2009]. The figures are calculated from tables on pages 18 and 24 , omitting the data from the School of Oriental and African Studies at the University of London.

27. Australian Research Libraries Collection Analysis Project, Report 2004: 41.

28. Ibid., 42.

29. Ibid., 50 .

30. Ibid., 47.

31. Ibid.

32. Kaye L. Baudinette, "The Flinders University and University of Adelaide Joint Library Store," Pathways to Knowledge: Australian Library and Information Association 5th Biennial Conference and Exhibition (Kingston: ALIA, 1999): 95-98.

33. Genoni, "Current and Future Print Storage for Australian Academic Libraries."

34. Philip D. Leighton and David C. Weber, Planning Academic and Research Library Buildings (Chicago: American Library Association, 1999).

35. National Library of Australia, A Guide to the Collection Assessment Process 2004. Available online at www.nla.gov.au/libraries/help/guide.html\#sl. [Accessed 23 February 2009].

36. Steve O'Connor, "The Economics of Repository Libraries in the Context of the Future Conventional Libraries," Library Management 26, no. 1/2 (2005): 22.

37. Ibid.

38. Genoni, "Current and Future Print Storage for Australian Academic Libraries."

39. The figure of 40.6 percent unique holdings can be compared to the result achieved by three North American universities (Duke, North Carolina State University, and the University of North Carolina) that comprise the Triangle Research Libraries Network (TRLN). A 2006 study of overlap among the libraries (across all classifications) found that 70 percent of holdings were unique (Triangle Research Libraries Network, 2006). This "better" result for the TRLN is the outcome of a long- established program of cooperative collecting. The results of the TRLN study are reported in Triangle Research Libraries Network, OCLC Collection Analysis Task Group, Report to the Committee on Information Resources (CIR) 2006. Available online at www.trln.org/TaskGroups/ CollectionAnalysis/TRLN_CollAnalysis_June2Report.pdf. [Accessed 23 February 2009].

40. As the lending data are derived from local systems, the same source has been used for the number of items available for loan. For all three libraries, this exceeds the number of items listed in Libraries Australia and used elsewhere in this paper. The explanation for this discrepancy appears to be that, whereas the Libraries Australia data have been limited to books (and are thereby suitable for calculating space savings), the local systems include books and other nonserial items.

41. Genoni, "Current and Future Print Storage for Australian Academic Libraries."

42. National Collaborative Research Infrastructure Strategy Committee, 2008 Review of the NCRIS Roadmap: Discussion Paper 2008: 52. 